\title{
The Polypeptides of Human and Mouse Coronaviruses
}

\author{
Brief Report \\ By \\ M. R. Macnaughton \\ Division of Communicable Diseases, Clinical Research Centre, \\ Harrow, Middlesex, England \\ With 3 Figures \\ Accepted August 9, 1979
}

\begin{abstract}
Summary
The polypeptide compositions of two coronaviruses, human coronavirus strain 229E (HCV 229E) and mouse hepatitis virus strain 3 (MHV 3), were characterised on polyacrylamide gels. Similar polypeptide patterns were observed for both viruses consisting of large surface projection glycopolypeptides of mol. wt. 160,000 and 105,000 for HCV 229E, and 170,000 and 90,000 for MHV 3, two small polypeptides of mol. wt. varying from 24,000 to 20,000, and a polypeptide of mol. wt. 50,000 . The results are discussed with respect to previous reports of the polypeptides of these and other coronaviruses.
\end{abstract}

Coronaviruses comprise a recently described group of viruses that have been characterised mainly on their similar unique morphology $(2,15)$. They are all large single stranded RNA viruses with lipid-containing envelopes ranging in diameter from 80 to $200 \mathrm{~nm}$ and possess widely-spaced club-shaped surface projections up to $20 \mathrm{~nm}$ in length (11).

The polypeptide composition of five coronaviruses have been described, namely: human coronavirus (HCV) strains 229E (6) and $\mathrm{OC} 43(7)$; mouse hepatitis virus (MHV) strains A59 $(3,13)$ and JHM $(3,16)$; avian infectious bronchitis virus $(\mathrm{IBV})(1,8,10)$; transmissible gastroenteritis virus (TGEV) $(4,5)$ and haemagglutinating encephalomyelitis virus (HEV) (12). Marked similarities were observed in the polypeptides of the HCV strains OC43 (7) and 229E (6), when they were purified and analysed by the same techniques in the same laboratory. Similarly, the polypeptides of the MHV strains JHMV and A59V (3), only differed slightly in mol. wt. when analysed under identical conditions. However, no close similarities have been observed previously between human and mouse coronaviruses, or between the polypeptides of any other coronaviruses. This may be due in part to the various methods used for virus growth and purification and poly- 
peptide analysis. Different conditions of preparation of MHV $(13,16)$ and IBV (8) can lead to major differences in the number and sizes of the polypeptides. Thus it is difficult to synthesize the coronavirus polypeptide data from these reports into a general description. A comparison of different coronaviruses in one laboratory using the same conditions of preparation and analysis is required to determine the relationship between the structural polypeptides of coronaviruses.

In this paper, the polypeptide characterisation of two coronaviruses, $\mathrm{HCV} 229 \mathrm{E}$ and MHV 3, is described, using the same conditions of purification and analysis. The polypeptide profiles of these viruses were similar. However, a comparison of these virus polypeptides with those of IBV strain Beaudette, also prepared using the same conditions of purification and analysis, revealed only minor similarities.

HCV 229E was grown in monolayer cultures of continuous MRC cells (derived from MRC5 cells) (9). For preparing labelled HCV $229 \mathrm{E}, 20 \mu \mathrm{Ci} / \mathrm{ml}$ of ${ }^{3} \mathrm{H}$-leucine or ${ }^{3} \mathrm{H}$-glucosamine $(20 \mathrm{Ci} / \mathrm{mmol}$ ) (Radiochemical Centre, Amersham) were added to the medium 4 hours after infection. MHV 3 was grown in confluent secondary mouse embryonic fibroblasts. The cell monolayers were infected at an input multiplicity of 0.1 infectious particles per cell and, following an adsorption period of 1.5 hours at $37^{\circ} \mathrm{C}$, were incubated for 72 hours at $37^{\circ} \mathrm{C}$ in Eagle's MEM with 2 per cent foetal calf serum. IBV Beaudette (IBV42) was grown in 10-day old embryonated chicken eggs or in confluent primary chick kidney cell cultures (8, 10). All virus preparations were clarified, pelleted, and purified on linear 25 to 55 per cent $(\mathrm{w} / \mathrm{w})$ sucrose density gradients at $4^{\circ} \mathrm{C}$ as previously described $(8,9)$.

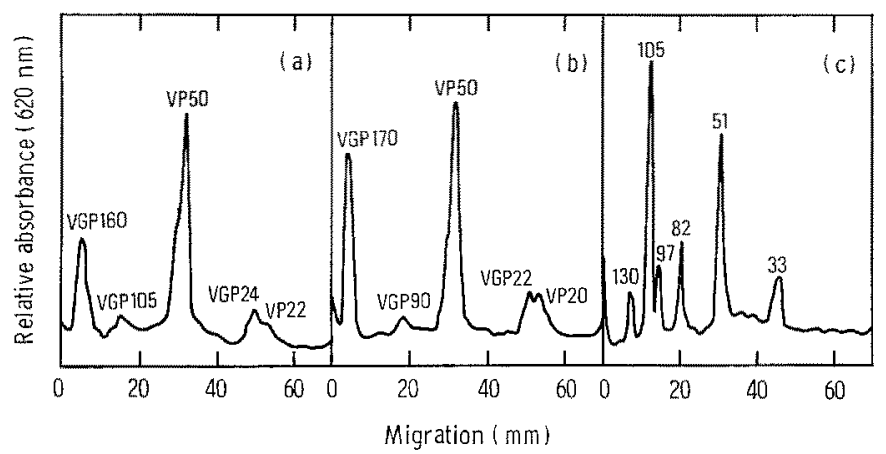

Fig. 1. Densitometer tracings of purified virus polypeptides on 7.5 per cent polyacrylamide gels after staining with Coomassie brilliant blue, $a$ HCV $229 \mathrm{E}, b$ MHV 3 , $c$ IBV Beaudette

Purified virus particles with densities of $1.18 \mathrm{~g} / \mathrm{ml}$ of $\mathrm{HCV} 229 \mathrm{E}, \mathrm{MHV} 3$ and IBV Beaudette were solubilised and reduced in 5 per cent SDS at $100^{\circ} \mathrm{C}$ for 1.5 minutes in 2 per cent 2 -mercaptoethanol and then analysed on polyacrylamide gels (8). Densitometer tracings of HCV 229E (Fig. 1a) and MHV 3 (Fig. 1 b) polypeptides stained with Coomassie brilliant blue revealed no major differences between them. Five major polypeptides were observed for both viruses, which were of similar mol. wt. and were present in approximately the same proportions. The mol. wt. of those polypeptides were calculated as described previously (8), using bovine serum albumin (dimer and monomer), ovalbumin, trypsin and lysozyme as 
markers. The approximate mean mol. wt. of the HCV 229E polypeptides, obtained from ten experiments, were $160,000,105,000,50,000,24,000$ and 22,000 , respectively, and the polypeptides were called VGP160, VGP105, VP50, VGP24 and VP22 (VP, virus polypeptide; VGP, virus glycopolypeptide - see below). Polypeptides of approximate mean mol. wt. of $170,000,90,000,50,000,22,000$ and 20,000 were obtained for MHV3 from ten experiments and these were called VGP170, VGP90, VP50, VGP22 and VP20 respectively. Occasionally, small amounts of material of mol. wt. about 56,000 and 36,000 were observed. However a different polypeptide structure was revealed for IBV Beaudette polypeptides (Fig. 1c), in which six polypeptides of mean mol. wt. 130,000, 105,000, 97,000, $82,000,51,000$ and 33,000 were observed as described previously (10), and have been called polypeptides 130, 105, 97, 82, 51 and 33 in Figure $1 \mathrm{c}$.

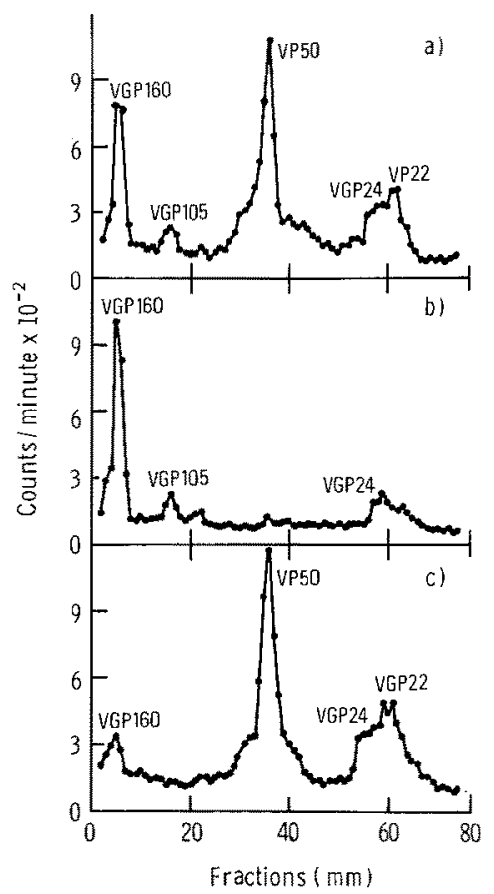

Fig. 2. Electrophoresis on 7.5 per cent polyacrylamide gels of purified HCV $229 \mathrm{E}$ polypeptides. $a^{3} \mathrm{H}$-leucine labelled, $b^{3} \mathrm{H}$-glucosamine laballed, $c^{3} \mathrm{H}$-leucine labelled and treated with w DTT at $4^{\circ} \mathrm{C}$

Virus preparations labelled with ${ }^{3} \mathrm{H}$-leucine or ${ }^{3} \mathrm{H}$-glucosamine were used to confirm the number and mol. wt. of the polypeptides and to identify which of them contained carbohydrate. Figure 2 a shows a profile of radioactivity in HCV $229 \mathrm{E}$ polypeptides labelled with ${ }^{3} \mathrm{H}$-leucine. Five peaks of radioactivity were clearly detected corresponding to those observed in the unlabelled preparations (Fig. 1a); although no components, corresponding to those sometimes seen in unlabelled preparations, were obtained. Figure $2 \mathrm{~b}$ shows profiles of radioactivity on polyacrylamide gels from ${ }^{3} \mathrm{H}$-glucosamine labelled HCV $229 \mathrm{E}$ particles. Three of 
the polypeptides, VGP160, VGP105 and VGP24 incorporated 3 H-glucosamine and hence contained carbohydrate. In all experiments the ratio of ${ }^{3} \mathrm{H}$-glucosamine to ${ }^{3} \mathrm{H}$-leucine, i.e. carbohydrate to amino acid content, appeared much lower in VGP24 compared to VGP 160 and VGP105. Similar labelled polypeptide profiles, corresponding to unlabelled profiles (Fig. 1 b), were obtained with $\mathrm{MHV}$, although generally the incorporation of both ${ }^{3} \mathrm{H}$-leucine and ${ }^{3} \mathrm{H}$-glucosamine into these virus particles was less satisfactory than for $\mathrm{HCV} 229 \mathrm{E}$.
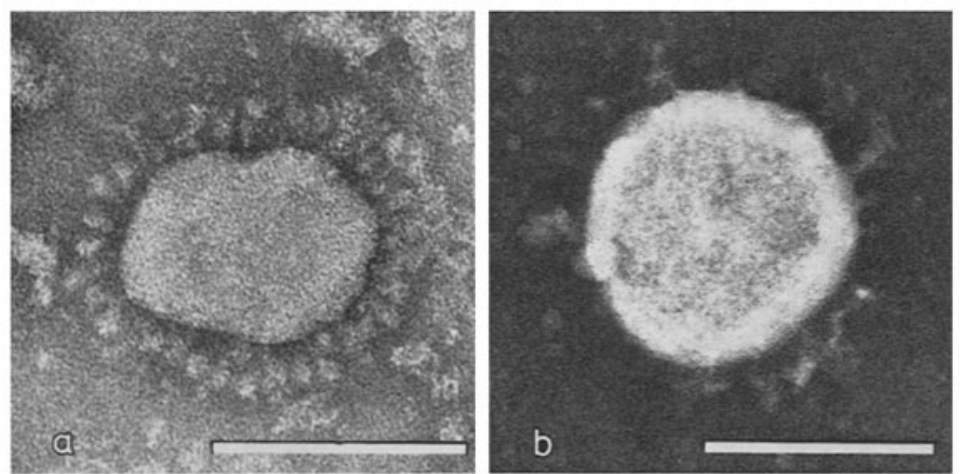

Fig. 3. HCV 229E particles of density $1.18 \mathrm{~g} / \mathrm{ml}$ from sucrose gradients. a untreated, $b$ suspended in M DTT at $4^{\circ} \mathrm{C}$. The bar represents $100 \mathrm{~nm}$

HCV 229E particles were suspended in $\mathrm{M}$ dithiothreitol (DTT) at $4^{\circ} \mathrm{C}$ and then purified by sedimentation on sucrose density gradients. Electron microscopy and polyacrylamide gel electrophoresis was done on peak virus fractions from these treated preparations in order to determine the effect of DTT incubation on virus structure. Figure 3 shows electron micrographs of untreated (Fig. 3a) and treated (Fig. $3 \mathrm{~b}$ ) HCV 229E particles. Most of the surface projections on treated virus particles were removed although a few projections remained. Increased concentrations of DTT or increased incubation temperatures with DTT removed all the projections, but also disrupted the virus envelope with a release of the ribonucleoprotein. Figure $2 \mathrm{c}$ is an electropherogram of the virus polypeptides after DTT treatment and a comparison with untreated virus polypeptides (Fig. 2a) shows that most of VGP160 and VGP105 are missing. This result suggests that these polypeptides comprise the surface projection polypeptides. Similar results were obtained with DTT treated MHV 3 preparations.

Previous studies of the composition of the structural polypeptides of $\mathrm{HCV}$ and MHV have shown them to have different polypeptide structures. Six to seven polypeptides were found in HCVOC43 and $229 \mathrm{E}$ of which only one was not glycosylated $(6,7)$, whilst only four to six polypeptides were obtained in MHVA59 $(3,13)$ and MHV JHM $(3,16)$, of which all but one $(3,14)$ or two $(16)$ were glycosylated. The mol. wt. and proportions of these polypeptides showed only superficial similarities. However, the results presented in this paper show that HCV $229 \mathrm{E}$ and MHV 3 have similar polypeptides when analysed under the same conditions. A comparison of these results and previous $\mathrm{MHV}$ reports $(3,13,14,16)$ indicate a similar polypeptide profile, in which the reported differences between workers 
are presumably caused by differences in virus growth and different conditions of polypeptide preparation and analysis $(8,13,16)$. In all cases, large glycopolypeptides apparently comprise the surface projections and are removed by bromelain or trypsin digestion or DTT incubation, and an unglycosylated internal polypeptide of mol. wt. 50,000 to 63,000 seems to comprise the internal component $(3,6,7,13,16)$. Furthermore, in all cases one or two polypeptides of mol. wt. ranging from 25,000 to 18,000 are present in purified virus particles. However, no major similarities are observed between our results and the previous $\mathrm{HCV}$ polypeptide reports $(6,7)$, although an unglycosylated polypeptide of mol. wt. 47,000 was observed in these reports which corresponds to our $50,000 \mathrm{~mol}$. wt. polypeptide.

It is of interest to compare the polypeptide patterns of $\mathrm{HCV} 229 \mathrm{E}$ and $\mathrm{MHV} 3$ with those reported for other coronaviruses. IBV, grown and analysed in this (8, 10) or other (1) laboratories, and $\mathrm{HEV}(12)$, have only minor similarities with $\mathrm{HCV}$ and MHV. On the other hand, the polypeptides of $\operatorname{TGEV}(4,5)$, consisting of a high mol. wt. surface projection glycopolypeptide, two low mol. wt. glycopolypeptides and an unglyoosylated internal polypeptide, show considerable similarity to HCV 229E and MHV 3.

In conclusion, it is suggested that the polypeptide structures of HCV $229 \mathrm{E}$ and MHV 3 are similar and consist of large surface projection glycopolypeptides of mol. wt. 160,000 and 105,000 for HCV 229 E, and 170,000 and 90,000 for MHV 3; two small polypeptides of mol. wt. varying from 24,000 to 20,000 ; and an internal component polypeptide of mol. wt. 50,000. Previous polypeptide profiles of MHV $(3,13,14,16)$ and TGEV $(4,5)$ agree with this pattern, although the coronaviruses, IBV $(1,8,10)$ and HEV (12) have different polypeptide structures. These results are important as they are the first to show a close similarity in the structural polypeptide composition between two coronaviruses, that infect different hosts and cause different diseases. This implies that there is a common polypeptide structure for at least some human and mouse coronaviruses, although this cannot be considered to be a model for all coronaviruses. Further work is required to clarify the relationship between the structural polypeptides of different coronaviruses.

\section{Acknowledgments}

Thanks are due to Miss M. H. Madge for preparation of the viruses, Mrs. H. A. Davies for electron microscopy and Dr. D. A. J. Tyrrell for his advice and criticism throughout these studies.

\section{References}

1. Alexander, D. J., Colurns, M. S.: The purification and polypeptide composition of avian infectious bronchitis virus. Microbios 18, 87-98 (1977).

2. Almeida, J. D., Berrey, D, M., Cunningham, C. H., Hamre, D., Hofstad, M. S., Matlucer, L., McIntosh, K., Trraetr, D. A. J.: Coronaviruses. Nature (Lond.) 220, 650 (1968).

3. Bond, C. W., Letbowrtz, J. L., Rose, J. A.: Pathogenic murine coronaviruses. II. Characterization of virus-specific proteins of murine coronaviruses JHMV and A $59 \mathrm{~V}$. Virology 94, 371-384 (1979).

4. Garwes, D. J., Pocook, D. H.: The polypeptide structure of transmissible gastroenteritis virus. J. gen. Virol. 29, 25-34 (1975). 
5. Garwes, D. J., Pocock, D. H., Pike, B. V.: Isolation of subviral components from transmissible gastroenteritis virus. J. gen. Virol. 32, 283-294 (1976).

6. HTERhotzen, J. C.: Purification and biophysical properties of human coronavirus 229E. Virology 75, 155-165 (1976).

7. Hierholzer, J. C., PAlmer, E. L., Whitrield, S. G., Kaye, H. S., Dowdle, W. R. : Protein composition of coronavirus OC 43. Virology 48, $516-527$ (1972).

8. Macnaughton, M. R., Madee, M. H.: The polypeptide composition of avian infectious bronchitis virus particles. Arch. Virol. 55, 47-54 (1977).

9. Macnadghton, M. R., Madge, M. H.: The genome of human coronavirus strain 229 E. J. gen. Virol. 39, 497-504 (1978).

10. Macnaughton, M. R., Madge, M. H., Davies, H. A., Dourmashizin, R. R.: Polypeptides of the surface projections and the ribonucleoprotein of avian infectious bronchitis virus. J. Virol. 24, $821-825$ (1977).

11. McIstosh, K.: Coronaviruses: a comparative review. Curr. Top. Nicrobiol. Immunol. 63, 85-129 (1974).

12. Pocock, D. H., GARWES, D. J.: The polypeptides of haemagglutinating encephalomyelitis virus and isolated subviral particles. J. gen. Virol. 37, 487-499 (1977).

13. Sturman, L. S.: Characterization of a coronavirus. I. Structural proteins: effects of preparative conditions on the migration of protein in polyacrylamide gels. Virology 77, 637-649 (1977).

14. Sturman, L. S., Holmes, K. V.: Characterization of a coronavirus: II. Glycoproteins of the viral envelope: tryptic peptide analysis. Virology 77, $650-660(1977)$.

15. Tyrreld, D. A. J., Alexander, D. J., Almeida, J. D., Cunningham, C. H., Easterdday, B. C., Garwhs, D. J., Hinrholzer, J. C., Kapikian, A., MacnaughTON, M. R., McIntosh, K.: Coronaviridae: Second report. Intervirology 10, 321 -328 (1978).

16. Wegt, H., Wmat, H., Nagasmima, K., Ter Meulen, V.: Stmuctural polypeptides of the murine coronavirus JHM. J. gen. Virol. 42, 37-47 (1979).

Author's address: Dr. M. R. Macnaughron, Division of Communicable Diseases, Clinical Research Centre, Watford Road, Harrow, Middlesex HA1 3 UJ, England.

Received June 21, 1979

Herausgeber, Eigentïmer und Verleger: Springer-Verlag, Mölkerbastei 5, A-1011 Wien. Für den Textteil verant wortlich: Dr. Wihelm Schwabl, Mölkerbastei 5 , A-1011 Wien. Für den Anzeigenteil versntwortheh: Mag. Bruno Schweder, Mölkerbastei 5, A-1011 Wien. Druck: R. Spies \& Co., Straußengasse 16, A-1050 Wien. Printed in Austria. 